\title{
THERMOSTABILITY OF LYTIC HETEROPHILE ANTIBODIES FROM HUMAN SERA INFECTED WITH Schistosoma mansoni AND GEO-HELMINTHS. AN IMMUNO-METRIC STATISTICAL ANALYSIS
}

\author{
Munir CHAMONE(1), Gregorio S. ATUNCAR(2) \& Paulo Marcos Zech COELHO(3,4)
}

\begin{abstract}
SUMMARY
Antibody in human sera that induces lysis of sheep erythrocytes in hemolytic assay was investigated. The present study showed that the presence in serum of the thermostable cytolytic anti-sheep red blood cells antibodies is dependent on the Schistosoma mansoni infection, and this is more frequent in adults than in children. The thermostable characteristic of hemolysins in normal sera was not dependent on the presence of Ascaris lumbricoides, Trichuris trichiura or hookworm geo-helminths. Further, thermostable complement-activating heterophile antibodies were noticed in children in association with massive number of $S$. mansoni eggs. The results were obtained by using the $\mathrm{z}$ - and the chi-square tests. The z-test allows us to formulate a one-sided alternative, i.e., a tendency of one of the attributes. On the other hand, the chi-square test analyzes the independence between attributes by using a contingency table. Besides the obtained results being interesting in the field of schistosomiasis mansoni, they can provide a new insight into the use of statistics in medical science.
\end{abstract}

KEYWORDS: Schistosoma mansoni; Heterophile antibodies; Thermostability; Lytic antibodies; Geo-helminths; Statistical tests.

\section{INTRODUCTION}

Herein, some aspects of the biological activity of the "naturally occurring" antibody in human sera, which lyses SRBC in a hemolytic assay, were investigated in schistosomiasis, such as the effect of heat treatment, as well as the association with age grade of individuals, faecal S. mansoni egg counts, and presence of certain geo-helminths.

Data analysis was certainly the basic part of group arrangement, as exemplified in a previous study with adult schistosomotic patients, the presentation displayed being important for functional antibody data visualization $^{2}$. For example, we can compare, by using small samples, groups of individuals with some immunoparasitological characteristics by means of numerical values. There are many reasons why statistical investigations in Immunology are matter of concern. Today, many medical journals require papers to contain appropriate statistical inference. Statistical methods, from the simplest ${ }^{1}$ to the most complex ones ${ }^{11}$ are often invoked for evaluating the results of quantitative determinations in parasite immunology as a whole. Thus, to interpret appropriately the results of an experiment or, in some sense, to extract from the data all the information they are capable of furnishing in relation to the question proposed, we are studying suitable methods that could be used ${ }^{8}$. It has been suggested that human anti-sheep red blood cells (SRBC) lysins were thermolabile, but became thermostable ${ }^{22,34}$. Here we analyze data about this observation, and care to definite conclusions, supported by extensive statistical analysis.

\section{MATERIAL AND METHODS}

Hemolysis test - The hemolysin tests with SRBC as target antigen were performed in sera collected from 69 individuals with positive stools for $S$. mansoni eggs, taking into consideration the presence of geo-helminths as well, using the Kato-Katz method ${ }^{20}$. Those individuals were divided into two age-groups: 32 children ( 8 to 15 -year-old) and 38 adults (20-year-old or more). A group of 10 children and 20 adults from the same area (with no history of water contact, no previous history of treatment for schistosomiasis and without geo-helminths) provided sera as a reference negative control. Those individuals were living in the surroundings of Belo Horizonte, State of Minas Gerais, Brazil, an endemic area for schistosomiasis. Sera were collected and used immediately. In order to make valid comparisons, the sera of schistosomotic individuals and controls were studied for the presence of lysins (naturally occurring complement activating macroglobulin antibodies) for $\mathrm{SRBC}^{2,9}$, in the following way: the natural hemolysin activity in each serum was assayed by mixing $1 \mathrm{~mL}$ of $1 / 20$ human serum with $0.5 \mathrm{~mL}$ of a $0.8 \% \mathrm{SRBC}$ suspension, which is spectrophotometrically standardized, and $2.0 \mathrm{~mL}$ of $1 / 400$ guinea-pig serum (complement source). The mixture was incubated at $37{ }^{\circ} \mathrm{C}$ for 30 minutes. The cells were sedimented by centrifugation and the hemolysis in the supernatant was estimated by measuring photometrically $(412 \mathrm{~nm})$ the amount of haemoglobin liberated. A control was performed for each experiment, replacing the complement 


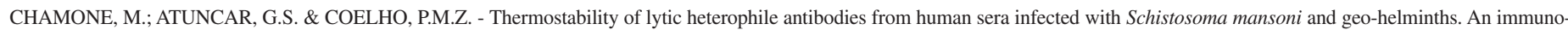
metric statistical analysis. Rev. Inst. Med. trop. S. Paulo, 48(3):157-165, 2006.

source with buffer or complement source previously heated for 60 minutes at $56{ }^{\circ} \mathrm{C}$ and containing $10^{-2} \mathrm{M}$ EDTA. The optical density of hemoglobin liberated by treating $0.5 \mathrm{~mL}$ of SRBC with $1 \mathrm{~mL}$ of distilled water and $2 \mathrm{~mL}$ of complement source was recorded and represented $100 \%$ lysis. The degree of hemolysis (hemolytic activity) was expressed as the percentage value calculated from the following formula: $100 \mathrm{x}$ absorbance of sample/absorbance of $100 \%$ hemolysis. In order to study the effect of each serum on heat treatment, a kinetic experiment was carried out as follows: $0.1 \mathrm{~mL}$ of serum sample in triplicate was kept at $56^{\circ} \mathrm{C}$ in water bath for only four or 60 minutes, than immediately cooled and diluted $1 / 20$ to be used in the hemolytic assay. Control sera were kept at $4{ }^{\circ} \mathrm{C}$. With this treatment, it was possible to distinguish three different groups among the sera from infected individuals. In the first group, sera were very labile, loosing more than $70 \%$ of their original anti-SRBC activity in only four minutes at $56{ }^{\circ} \mathrm{C}$ ( $\mathrm{L} 4$ serum lysin type). Another group included sera whose activity remained practically unchanged for 30 minutes and the residual cytolytic antibody against SRBC was more than $30 \%$ after heating for 60 minutes (R60 serum type). Finally, an intermediary group was identified presenting a gradual loss of its hemolytic activity after heating at $56{ }^{\circ} \mathrm{C}$ for more than four minutes (R4 serum), loosing more than $70 \%$ of their original anti-SRBC activity in 30 minutes at $56{ }^{\circ} \mathrm{C}$. Data were statistically analyzed by methods described below.

Statistical analyses - The "z" test for a single sample proportion to test the null hypothesis that the sample proportion is some prespecific value ${ }^{16}$ was used to test if the proportion of thermostable antiSRBC lysins in children is 0.8 , the same observed in adults. A CochranArmitage's device was used to test if the hemolysin classification as L4, R4 or R60 presents the same trend ${ }^{29}$ in children and in adults with schistosomiasis mansoni. We used the Cochran statistical test ${ }^{4}$ to compare the proportions of schistosomotic individuals with geohelminths, in children and adults strata, by thermal characteristic of hemolysins. The Mood's median method ${ }^{17}$ and the G-test ${ }^{30}$ were used to investigate whether labile and not labile hemolysins can be associated with the intensity of S. mansoni infection measured by faecal egg counts. An extension of the median method (the quartile test) was used to test equality of proportions against a trend across quartile groups in the thermostable anti-SRBC lysins in children group. Thus, we used Armitage's test for trend ${ }^{7}$. When trend was not considered, a test of homogeneity (the Pearson chi-squared test) was used to detect differences between the observed proportions. Finally, when geohelminths species will be a third variable ${ }^{11}$ in addition to the variables age-grade and hemolysin groups the data can be represented in a three dimensional contingency table easy to visualize what happens in the strata or subgroups ${ }^{15,35}$.

\section{RESULTS}

1) We studied the heating effect on serum hemolysins. The sera were collected from 32 children expelling S. mansoni eggs in faeces. When these sera were heated at $56{ }^{\circ} \mathrm{C}$ for one hour, their cytolytic antibodies against SRBC in a hemolytic assay were completely destroyed in 18 out of 32 sera $(57.58 \%)$, but not in 14 sera $(42.42 \%)$. All the information on the question of proportions is contained in the numbers 18 and 14 .

According to a previous study ${ }^{9}$ about heating effects on heating stability of naturally occurring hemolytic antibodies against SRBC in serum of schistosomotic patients, about $20 \%$ of the adult individuals exhibited the character of thermolability under a specific condition, but $80 \%$ did not. Therefore, if there was any effect of heating on the children serum hemolysins, it would be expected that children in the present experiment could be split similarly on the average 20:80 between the categories thermolabile and thermostable. With the present study, we wish to know whether the present result is consistent with a previous work or not. Further, we want to know whether the observed proportion of $14 / 32$ (or $43.75 \%$ ) in children is statistically the same as that found in a previous study with adults $(80 \%)$ rather than significantly different than $80 \%$. The " $\mathrm{z}$ " test for a single sample proportion to test the null hypothesis that the sample proportion is some pre-specific value, where $1 / 2 n=1 / 64$ represents the continuity correction, is:

$|z|=\frac{(0.4375-0.800)-1 / 64}{\sqrt{(0.80)(1-0.80 / 32}}=5.35$

This absolute value of " $z$ " equal to 5.35 is higher than the critical value given by standard normal distribution, when a two-sided test, at 0.05 significant level is used. Then, the obtained $\mathrm{z}$ value of 5.35 is enough to give a significant result with $\mathrm{p}<0.001$ in a comparing proportion in single sample test regardless of the direction predicted (that is, irrespective to sign the operation since it is a two-tailed test). For one-sided test (considering that $43.75 \%$ is higher than standard $80 \%$ rather than only different of them) consider the sign of the difference obtained by operation.

In conclusion, the data clearly indicate that there is a real difference between the children and adult porportions, then it should be expected that the frequencies 18 and 14 are not related as 20:80. We can conclude that in schistosomotic children there is a predominance of thermolabile antibody, while in schistosomotic adults there is a predominance of thermostable antibody. This can be caused by some unknown biological phenomenon, but age is a variable very important in medical investigation. Remark: The real proportion of thermostabile hemolysins in adults is unknown, but as a sample size is large $\mathrm{e}^{2,9}$, we used the estimated proportion as a real proportion in adult schistosomotic individuals.

2) Previous observations on schistosomotic adult individuals in a kinetic study showed that three patterns could be observed after heating of the sera, namely L4, R4 and R60 to be described bellow ${ }^{2,9}$ : a decrease of more than $70 \%$ of hemolysin activity after heating for four minutes at $56{ }^{\circ} \mathrm{C}$ was observed in the first group (L4 serum type). The second group (R4 serum type) did not alter after heating for four minutes, but a sharp decrease was observed after 30 minutes, and following 60 minutes a loss of more than $70 \%$ of the hemolysin activity was also observed. The third group (R60 serum type) did not show any alteration after 60 minutes, the serum persisted with more than $70 \%$ of the hemolysin activity. These investigations on adults are extended to children because, as shown in a previous result, thermostable percentage of $57.58 \%$ might be considered to be possibly confounded with age grade. From further investigations in schistosomotic children, the majority 18 out of $32(56.25 \%)$ showed hemolysins of L4 type, 13 (40.63\%) were R4 type and only one (3.13\%) was R60. These patterns, however, could be distinguished from that presented by 38 adults with S. mansoni infection, as follows: $10(26.32 \%)$ were L4 type, 10 


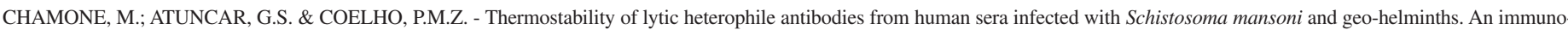
metric statistical analysis. Rev. Inst. Med. trop. S. Paulo, 48(3):157-165, 2006.

Table 1

A device to compute trend among frequencies of serum hemolysin types in children and adults with schistosomiasis mansoni

\begin{tabular}{lcccccccc}
\hline Sera & Scores S & Children C & Adults & Total T & C/T & SxC & SxT & S \\
\hline L4 & 0 & 18 & 10 & 28 & 0.6429 & 0 & 0 & 0 \\
R4 & 1 & 13 & 10 & 23 & 0.5000 & 13 & 23 \\
R60 & 2 & 1 & 18 & 19 & 0.0526 & 2 & 38 \\
Totals & & 32 & 38 & 70 & & 15 & 61 & 96 \\
\hline
\end{tabular}

(26.32\%) R4 and $18(47.37 \%)$ R60 type.

The hemolysin groups are in natural order of thermostability, that is, Labile (L4 serum) $\rightarrow$ Intermediary (R4 serum) $\rightarrow$ Resistant (R60 serum). There is a trend in the probabilities whose observations fall into a series of ordered categories that may be used to evaluate the immunological state of the patient. Table 1 summarizes the data arranged in the natural order of the treatment variable, which was replaced by scores, as follows:

Kinetic studies about the heating effect on serum hemolysins suggest that the antibody activity in schistosomotic adults tend to be in a higher proportion than that in schistosomotic children. The question of interest is whether thermo characteristics of children hemolysins change differently from those in adults. The formula for the statistics based in $\chi^{2}$ distribution with one degree of freedom is:

$$
x^{2}=\frac{\left(15-\frac{32(61)}{70}\right)^{2}}{\frac{32}{70}\left(\frac{38}{70}\right)\left(99-\frac{61^{2}}{70}\right)}=14.59
$$

The statistics $\chi^{2}=14.59$ is higher than 3.84 , a value that is associated with the more traditional choice of the significance level, the $0.05 \mathrm{cut}$ off point. Then, the obtained $\chi^{2}$ value of 14.59 is enough to give a significant result with $\mathrm{p}<0.001$. In conclusion, there is a strong trend which results in different direction variation in the proportion of children as we change to more thermolabile antibody activity. The probability of thermostability decreases with decreasing age grade.

Since the stability of heterophile antibodies activity is not the same within the age grade, there is a "pulsed complement activating antibody activity" in an antibody population generally considered as spurious one. More important than isolated frequencies is the report on the ability for schistosomiasis to respond to fluctuating antibodies activity and persistence. Finally, the design represented here has not been clearly distinguished in textbooks of statistics. Research workers should not apply unappropriate methods, such as the common chi-square test.

3) Further, it was considered relevant to investigate the relationship among geo-helminths, age grade and thermostability of hemolysins. Thus, geo-helminths will be a third variable in addition to the variables age grade and hemolysin groups. In epidemiological studies, there are some situations on which it is useful to investigate a particular aspect of the data, i.e., the significance of cases harboring geo-helminths (positive cases). In fact, it is known that children are more frequently infected by geo-helminths than adults. Then, the age related with geohelminths can be a confounding factor in hemolysin investigations rather than schistosomiasis itself. In this way, it is relevant and useful to investigate the relationship among age grade, hemolysin activity and presence of geo-helminths, considering the latter a confounder. In statistical sense, this implies hypothetically that the hemolysin thermal characteristics do not influence or are not influenced by geo-helminths situation in any age grade. This has not been commonly investigated in Immunology and, therefore, association or lack of it among age grade, hemolysins and geo-helminths situation is of obvious medical interest. For this type of question we can use the Cochran statistical test. The data was arranged to compare the positive cases (referred as "+") of geo-helminths on samples by application of a shortcut computation for non statistician investigator:

By visual inspection of the data depicted on combined tables (children and adults), the presence of geo-helminths possibly is more frequent in children with more labile hemolysins than in similar adults. Therefore, all the information about the presence of geo-helminths is contained in the question: Are the positive geo-helminths mean differences $0.9444-0.4000=0.5444,0.6923-0.3000=0.3923$ and 0.000 $0.333=-0.3333$ through hemolysin classes statistically different?. If statistical test shows significant difference among geo-helminths

Table 2

Comparison between the proportion of schistosomiasis persons with geo-helminthes $(+)$, in children and adults strata, across thermal characteristic of the sera hemolysins L4 ( $=18), \mathrm{R} 4(\mathrm{n}=13)$ and R60 $(\mathrm{n}=1)$

\begin{tabular}{|c|c|c|c|c|c|c|}
\hline \multirow[b]{2}{*}{ Sera } & \multicolumn{2}{|c|}{ Children $(\mathrm{n}=32)$} & \multicolumn{2}{|c|}{ Adults $(\mathrm{n}=38)$} & \multicolumn{2}{|c|}{$\begin{array}{l}\text { Positive and negative } \\
\text { geo-helminths by sera group }\end{array}$} \\
\hline & $+/$ Total & $\%+$ & $+/$ Total & $\%+$ & All “+” & All “_“" \\
\hline L4 & $17 / 18$ & 0.9444 & $4 / 10$ & 0.4000 & $21 / 28$ & $7 / 28$ \\
\hline $\mathrm{R} 4$ & $9 / 13$ & 0.6923 & $3 / 10$ & 0.3000 & $12 / 23$ & $11 / 23$ \\
\hline R60 & $0 / 1$ & 0.0000 & $6 / 18$ & 0.3333 & $6 / 19$ & $13 / 19$ \\
\hline
\end{tabular}




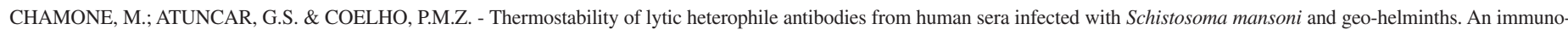
metric statistical analysis. Rev. Inst. Med. trop. S. Paulo, 48(3):157-165, 2006.

proportions, then there is association in each hemolysin group and age grade. Our shortcut formula for the statistics based in $\mathrm{z}$ distribution is:

$\mathrm{z}=\frac{(0.5444) 18 \times 10 / 28+(0.3923) 13 \times 10 / 23+(-0.3333) 1 \times 18 / 19}{\sqrt{ }\left(18 \times 10 \times 21 \times 7 / 28^{3}\right)+\left(13 \times 10 \times 12 \times 11 / 23^{3}\right)+\left(1 \times 18 \times 6 \times 13 / 19^{3}\right)}=\frac{5.389}{\sqrt{ } 2.820}=3.21$

This is approximately a " $\mathrm{z}$ " statistic, and it is significant $(\mathrm{p}=0.002$, two-sided test). In conclusion, there is a significant difference among the geo-helminths proportions in the three hemolysin groups through two age grades. If the statistical test of independence shows that the properties are not independent, it will be inferred that one of the attributes distribution is more likely than the other. Also, the designs represented here have not been clearly distinguished in textbooks of statistics, and research workers can not ignore data when two tables are combined (children and adults data).

4) A predominant feature in immunopathology of schistosomiasis mansoni, in regard of the intensity of the disease, is the number of eggs embolised in the liver. Thus, it was investigated if the hemolysin serum groups may be associated with the faecal egg counts, a measure of schistosomiasis intensity. Ignoring, for the moment, the complete kinetic studies on the loss of hemolytic activity by heating effects, it was possible to distinguish two different groups among the sera from schistosomotic children: a group included sera whose activity was destroyed after heating for four minutes (Labile serum, $\mathrm{n}=18$ ) and a group remained practically unchanged (Not labile serum, $n=14$ ). If two characteristics are present (labile and not labile antibodies), it is logical to investigate whether they can be associated with the intensity of $S$. mansoni infection measured by faecal egg counts.

Besides the mean, the median is widely used to describe the location of a set of data, and then it can be used to test if labile and not labile hemolysin groups come from populations which have the same median egg counts. The median of a population has the property that at least half of the values in the population exceeds it, and at least half falls short of it. This leads to a fourfold table: scores which exceed the median versus those which do not exceed the median in each group.

A sample of 32 children provides the $S$. mansoni egg counts per gram of faeces in 18 labile and 14 not labile group with the following scores: 1) Labile hemolysin group (L4 serum) $=12$, 12, 12, 24, 24, 36, 36, 36, 36, 36, 48, 72, 106, 120, 120, 180, 360, 744; 2) Not labile hemolysin group $(\mathrm{R} 4+\mathrm{R} 60$ sera $=12,12,36,48,84,120,144,216$, $278,288,288,300,530,878$. The grand median is $(72+84) / 2=78$. As far as the application of the Mood's median test is concerned, it will be expected to divide the scores (egg counts) from any of the two

Table 3

Schistosomotic children stratified by serum hemolysins and by distribution of secretors of Schistosoma mansoni egg counts falling below or above the median 72 faecal egg counts

\begin{tabular}{|c|c|c|c|}
\hline \multirow[b]{2}{*}{ Hemolysins } & \multicolumn{3}{|c|}{ Distribution around the median } \\
\hline & Not above & Above & Total \\
\hline Labile & 12 & 6 & 18 \\
\hline \multirow{2}{*}{ Not labile } & 4 & 10 & 14 \\
\hline & 16 & 16 & 32 \\
\hline
\end{tabular}

samples likely to be above median or not. The number of children located around the grand median 78 egg counts is:

It is very important to know about the origin of the data. In this case, the sample size 32 has not been collected by obtaining a random sample intentionally consisting of some specified number of observations below or above any median egg counts, and tabulating how many of each of those groups fall above or below the median. Here, a random sample of 32 schistosomotic children was obtained in order to investigate whether scores on thermolabile and thermostable groups are related. At the beginning of the study, it was fixed 32 as sample size and not the totals of above or below trial distributed between two groups of egg count median.

Since the totals of 18 and 14 for rows and the total 16 and 16 for columns are not specified in advance, the test is named a test of independence (association), rather than test of homogeneity. So far, it was intended to see whether the frequency distribution of individuals classified according to the hemolysin situation is independent of the median of egg counts. The G-test of independence is based on the totals in the margin of the table used. The designs represented here have not been clearly distinguished in textbooks of statistics and research workers have been applying the $\mathrm{G}$ test and $\mathrm{x}^{2}$ test indifferent of the appropriated design ${ }^{30}$.

If the proportion of individuals that falls above or below the median was not fixed by the researcher, but was an outcome of the experiment, the G-statistic is (where the number 2 is a constant):

$\mathrm{G}=2\{[12 \ln 12+61 \mathrm{n} 6+4 \ln 4+10 ! \mathrm{n} 10]-[161 \mathrm{n} 16+161 \mathrm{n} 16+181 \mathrm{n} 18$
$+14 \ln 14+321 \mathrm{n} 32]+32 \ln 32\}$
$\mathrm{G}=2\{[69.1404]-[177.6963]+[110.9035\}$
$\mathrm{G}=2\{2.3476\}=4.695$

William's correction, is preferable when the G test is $\geq 3.84$ G with William's correction $=\frac{4.695}{1+\frac{1}{6(32)}\left[\left(\frac{32}{16}+\frac{32}{16-1}\right)\left(\frac{32}{18}+\frac{32}{14-1}\right)\right]}$

(Where the figures $1,-1$ and 6 are constants)

The $\mathrm{G}$ values are approximately distributed as $\mathrm{x}^{2}$ with one degree of freedom. The statistic $\mathrm{G}=4.481$ is higher than 3.84 , a value that is associated with the 0.05 cut off point. The higher the value of chisquare the lesser the probability and hence the stronger the evidence that the equal splits are untrue. Then, it provides evidence that the two hemolysin groups do not come from children that have the same median: the egg counts in the non labile hemolysin sample exceed the labile ones. In other words, the distribution of egg counts around the grand median of egg counts is dependent of the hemolysin groups, at least with the range of the present experiment.

In conclusion, six out of 18 or $33 \%$ of labile cases falling in higher egg counts (above the median) is statistically different from 10 out of 14 or $71 \%$ of nonlabile cases falling in higher egg counts. This is the answer to the question "Is the percentage distribution of children through the median egg counts independent of the hemolysin groups at conventional $5 \%$ significant level?" The test of independence will 
not test whether scores occur at a given proportion, but can test only whether the lower and higher scores are independently manifested.

5) From quantitative egg counts performed on labile and non-labile children groups, the arithmetic mean \pm standard deviation on egg count for labile hemolysin group was $111.9 \pm 179.2$, with non-labile group averaging more than twice, $231.0 \pm 237.1$. Then, the intensity of infection was numerically seen higher in 18 labile than in 14 nonlabile cases of hemolysins.

An extension of the median test is the quartile test. This one examines, for each sample, how many values (proportions) are above or below specified quartile rather than the median only. Table 3 records the group quartiles GQ for the pooled children samples of the total size 32. Each number represents the number of observations in the corresponding quartile class for labile and non-labile groups. Remark 1: for a sample, the first quartile is defined as that value from which at least $25 \%$ of the observations are below or equal to Q1, and at least $75 \%$ are above or equal to Q1. Similarly, Q2 and Q3 are defined. Remark 2: the first quartile class (QC1) is formed by all observations below or equal to Q1. The second quartile class (2) is formed by all observations above Q1 and below or equal to Q2. Similarly, the third (QC3) and fourth (QC4) quartile classes are defined. The frequencies that have already been selected for cells in $2 \times 4$ table are presented in Table 3 .

Table 4

Frequency distributions in quartile groups of egg counts in the experiment (illustrated with percentages)

\begin{tabular}{llllll}
\hline Hemolysins & QC1* & QC2 & QC3 & QC4 & Total \\
\hline Labil & 10 & 2 & 4 & 2 & 18 \\
Not labil & $3(30 \%)$ & $1(33.3 \%)$ & $4(50 \%)$ & $6(75 \%)$ & 14 \\
& 13 & 3 & 8 & 8 & 32 \\
\hline
\end{tabular}

*Quartile classe.

The two groups of serum hemolysins distributed on quartile categories are obviously ordered (QC1 through QC4). Trend assessment has been frequently reported in the literature. Thus, trends can be incorporated into the present analysis to be applicable in a problem of immunoparasitology, such as monitoring of sequence of $S$. mansoni egg counts. It is well established in schistosomiasis that in an egg counting more individuals tend to be located in lower egg count classes than in larger ones. Therefore, the direction was indicated and using an one-sided statistics it was intended to investigate if the hemolysin group affects the number of children over the sequence of median intervals of egg counts. Then we are intended to investigate if the proportions of individuals classified as thermostable hemolysin also decreased across quartile classes. The procedure of the statistic $\mathrm{S}^{*}$ for trend in proportions in $2 \mathrm{xC}$ table is:

$$
\begin{aligned}
& A=10(1+4+6)+2(4+6)+4(6)=154 \\
& B=3(2+4+2)+1(4+2)+4(2)=38 \\
& S=A-B=154-40=116(\text { mean deviation) } \\
& \Sigma n^{3}=13^{3}+3^{3}+8^{3}+8^{2}=3221 \\
& N=32 \text { (with subsamples of size } 18 \text { and } 14)
\end{aligned}
$$

Standard deviation $=\frac{\sqrt{18(14)\left(32^{3}-3221\right)}}{3(32)(32-1)}=\sqrt{2,499.68}=49.99$

(Where figures 3 and -1 are constants)

Thus, $\mathrm{S}^{*}=\frac{116}{49.99}$ (“z"distribution, $\mathrm{p}<0.01$ )

This is enough to suggest an increasing (since $S$ is positive) trend in egg counts for group of thermostable hemolysins. From the results, the conclusion is that there is a trend in proportions, while labile group decreases the not labile group increases. The trend test is important to obtain information about the functional form of an egg output sample from schistosomotic individuals, whose variability of egg counts (intensity of infection) is studied. In fact, the trend test is more powerful than the Pearson chi-squared (common $\chi^{2}$ ) test, when applied to data where the later is applicable. A quicker method of computing common $\chi^{2}$ test of homogeneity and independence (not testing for a trend) in larger tables is as follows:

$x^{2}=32\left[\left(\frac{10^{2}}{13}+\frac{2^{2}}{3}+\frac{4^{2}}{8}+\frac{2^{2}}{8}\right) \frac{1}{18}+\left(\frac{3^{2}}{13}+\frac{1^{2}}{3}+\frac{4^{2}}{8}+\frac{6^{2}}{8}\right) \frac{1}{14}\right]-32=5.69$

Chi-square tables show that for $(2$ rows- 1$) \times(4$ collumns -1$)=3$ degrees of freedom, $\mathrm{p}$ (chi-square $=5.69$ ) is less than conventional 0.05 (the tabled number is 7.81). Hence, the differences are not significant at the chosen significant level, and then not great to be explained in terms of random variations only. It is important to note that this common $\chi^{2}$ statistic refers only to the homogeneity or not among proportions, therefore not testing for a trend. When applicable, the quicker method of computing $\chi^{2}$ was very appropriate. In fact, statistical methods may be relatively less complex to account for the non-professional experimental analysis and interpretation of the data. Therefore, it is presented a shortcut formulae of $\chi^{2}$ for $2 \mathrm{x} \mathrm{k}$ treatments. The shortcut chi-square formula as a version of the formula for common $\chi^{2}$ is mathematically identical to the general formula $x^{2}=\Sigma\left[(\mathrm{O}-\mathrm{E}]^{2} / \mathrm{E}\right\}$.

6) In previous sections the presence of geo-helminths as a fact was introduced, but not the geo-helminth species. Some aspect of the study may be lost if we do not consider the species of geohelminths. Further, it was relevant and useful to investigate the relationship between some geo-helminths species - broken by two grand groups, namely hookworm (H) positive and $\mathrm{H}$ negative or Ascaris lumbricoides (As) plus/or Trichuris trichiura $(\mathrm{T})$ - age-grade and thermostability of hemolysins. So far, geo-helminths species will be a third variable in addition to the variables age-grade and hemolysins groups.

First of all, hemolysins were preliminarily investigated in nonschistosomotic individuals. Naturally occurring cytolytic anti-SRBC antibodies in 10 children without geo-helminths and 11 adults (in whose stools the presence of A. lumbricoides, T. trichiura, and/or hookworms was detected). All these individuals presented L4 lysin in serum and, then, no thermostabile lysins were found in these schistosomotic cases. Thus, the presence of geo-helminths might not be associated with thermostable lysins in non-schistosomotic serum.

Further, in schistosomotic individuals with geo-helminths, a third dimension is added for analysis of data with three responses in a threeway-table, so we have a three dimensional contingency table. In 


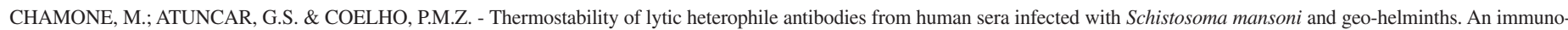
metric statistical analysis. Rev. Inst. Med. trop. S. Paulo, 48(3):157-165, 2006.

statistical sense, this implies that the antibody characteristics does not influence or are not influenced by geo-helminths status through age grade in a test of significance. This type of approach is not previously reported in Immunology, therefore association or lack of it among age grade, hemolysins and some geo-helminths species are therefore of obvious medical interest.

In Epidemiology, it is very important to employ methods to test whether two different attributes, i.e., two age-grades, each of them occurring under two conditions (labile and not labile hemolysins) related to geo-helminths species are dependent from one another. If the statistical test of independence in a three dimensional contingency table shows that the properties are not independent, this will lead to the conclusion that one of the property distribution is more likely than the other. The data can be represented in a three dimensional contingency table easy to visualize what happens in the strata (subgroups). Statistically, the expectation is that the proportion on each level of the attribute is not different than the proportion of another level of attribute. In Biology, is very important to employ a method to test whether different properties, each occurring under different conditions, are dependent from one another. If any properties are not independent from one another, they are associated. If individual strata (two age grades) are classified by thermostability of hemolysins into two classes, and by a second characteristic (geo-helminths: $\mathrm{H}$ group = hookworm; As/T group = Ascaris and/or Trichuris; Neg = negative) into three classes, the data may be presented in a relatively complex $\chi^{2}$ table with strata bearing on the same question, as follows (for convenience some totals are in bold face):

In this $2 \times 2 \times 3$ contingency table there are cross-classification of CFT (two levels), age (two levels) and a third variable (geo-helminths, with three levels) whose effects we want to control because of their possible influence on that relationship. Then, it is of interest a comparison between the proportion of schistosomotic individuals with no labile hemolysins, in children and adults strata, $43.7 \%$ and $73.7 \%$, respectively, through three geo-helminths conditions. The statistics is an extension of the common chi-square calculation in spite that some expected frequencies are small ${ }^{11}$. The computations of the expected frequencies under the hypothesis of independence of the three grand group of variables differs from common $\chi^{2}$ test of variables and, then, are calculated in the following manner:

$\underline{\text { Total for age grade } \mathrm{x} \text { total for lysin group } \mathrm{x} \text { total for geo-helminth conditions }}$ $70^{2}$
So far, the computation of statistics involves a previous knowledge of the children group total $(n=32)$, the adult group total $(n=38)$, for the lysine groups total $($ Labile $=! 8$ children +10 adults $=28$; Not labile $=14$ children +28 adults $=32$ ) and of the geo-helminth group totals (for $\mathrm{H}$ is 12 children +10 adults $=22$, for $\mathrm{As} / \mathrm{T}$ is 14 children +3 adults $=17$, for Neg is six children +25 adults $=31$ ) where 70 is the total in the table.

The statistic test to control for two levels of age, two levels of lytic antibodies and for three level of geo-helminths conditions proceeds as follows:

a) Application of the general $\chi^{2}$ formula, $\Sigma\left[(\mathrm{O}-\mathrm{E})^{2} / \mathrm{E}\right]$, for partition of chi-square for children or adults groups (the observed frequencies are in bold), with partial associations for labile level $\left(\mathrm{x}_{\mathrm{L}}^{2}\right)$ and for not labile level $\left(\mathrm{x}_{\mathrm{N}}^{2}\right)$ :

For children:

$$
\begin{aligned}
& \mathrm{x}_{\mathrm{L}}{ }_{\mathrm{L}}=\frac{\left(6-32 \times 28 \times 22 / 70^{2}\right)^{2}}{32 \times 28 \times 22 / 70^{2}}+\frac{\left(11-32 \times 28 \times 17 / 70^{2}\right)^{2}}{32 \times 28 \times 17 / 70^{2}}+\frac{\left(1-32 \times 28 \times 31 / 70^{2}\right)^{2}}{32 \times 28 \times 31 / 70^{2}}=24.5496 \\
& \mathrm{x}^{2}{ }_{\mathrm{N}}=\frac{\left(6-32 \times 42 \times 22 / 70^{2}\right)^{2}}{32 \times 42 \times 22 / 70^{2}}+\frac{\left(3-32 \times 42 \times 17 / 70^{2}\right)^{2}}{32 \times 42 \times 17 / 70^{2}}+\frac{\left(\mathbf{5}-32 \times 42 \times 31 / 70^{2}\right)^{2}}{32 \times 42 \times 31 / 70^{2}}=2.0362
\end{aligned}
$$

Where the partition of chi-square for children group is $24.5496+2.0362$ $=26.5858$

For adults:

$$
\begin{aligned}
& \mathrm{x}_{\mathrm{L}}^{2}=\frac{\left(\mathbf{2}-38 \times 28 \times 22 / 70^{2}\right)^{2}}{38 \times 28 \times 22 / 70^{2}}+\frac{\left(2-38 \times 28 \times 17 / 70^{2}\right)^{2}}{38 \times 28 \times 17 / 70^{2}}+\frac{\left(6-38 \times 28 \times 31 / 70^{2}\right)^{2}}{38 \times 28 \times 31 / 70^{2}}=2.1690 \\
& \mathrm{x}^{2}{ }_{\mathrm{N}}=\frac{\left(\mathbf{8}-38 \times 42 \times 22 / 70^{2}\right)^{2}}{38 \times 42 \times 22 / 70^{2}}+\frac{\left(\mathbf{1}-38 \times 42 \times 17 / 70^{2}\right)^{2}}{38 \times 28 \times 17 / 70^{2}}+\frac{\left(19-38 \times 42 \times 31 / 70^{2}\right)^{2}}{38 \times 42 \times 31 / 70^{2}}=11.6839
\end{aligned}
$$

Where the partition chi-square for adults group is $2.1690+11.6839=$ 13.8529

c) Chi-square test total is the sum: $26.58+13.85=40.43$

d) Computation of degrees of freedom (number 2 in bold is constant): 2 age grades $\mathrm{x} 3$ geo-helminth conditions $\mathrm{x} 2$ hemolysin groups (or 2 rows) $-2-3-2+2=7$

Table 5

Presence of geo-helminths species in stool examinations to compare their distributions on children and adults with schistosomiasis mansoni, with classification by thermal sensibility of hemolysins

\begin{tabular}{lccccccccc}
\hline & \multicolumn{4}{c}{ Children } & \multicolumn{4}{c}{ Adults } \\
Lysins & $\mathrm{H}$ & $\mathrm{As} / \mathrm{T}$ & $\mathrm{Neg}$ & Total & Geo-helminths \\
As/T & Neg & Total & Totals for \\
Labil & 6 & 11 & 1 & $18(56.3 \%)$ & 2 & 2 & 6 & $10(26.3 \%)$ & 28 \\
Not labil & 6 & 3 & 5 & $14(43.7 \%)$ & 8 & 1 & 19 & $28(73.7 \%)$ & 42 \\
& 12 & 14 & 6 & $32(100 \%)$ & 10 & 3 & 25 & $38(100 \%)$ & 70 \\
\hline
\end{tabular}

$* \mathrm{H}=$ Hookworm; As/T = Ascaris and/or Trichuris; Neg = negative for geo-helminths. 
e) The value of $\chi^{2}=40.43$ is then converted to a $p$-value as the common $\mathrm{x}^{2}$ test on table with 7 degrees of freedom), and $\mathrm{p}<0.005$.

In conclusion, the analysis of data with three responses per unit reveals that there is a high association between the attributes. In other words, age grade, geo-helminths species and thermosensitivity of hemolysins are not all mutually independent in the population: there is an association between the thermosensibility of hemolysins and the geo-helminths species through age grade, at least with the range of the experiment. There is a difference between the geo-helminths species proportions in the two hemolysin groups in an immunological investigation to compare the effect of geo-helminths species with classification of schistosomotic individuals by age grade. There is a significant association between the labile hemolysin group and presence of geo-helminths species. If the statistical test of independence shows that the attributes are not independent, it will be concluded that one of the property distribution is more likely than the other. The designs represented here have not been clearly distinguished in textbooks of statistics. Research workers can not ignore difference between groups, when two tables are combined (children and adults with their respective attributes).

\section{DISCUSSION}

As can be seen in the literature, the phenomenom of antibody in human sera which lyses sheep erythrocytes in the presence of complements in sera of schistosomotic children and adults has been insufficiently investigated up to now ${ }^{2,9}$. It has been reported that in the earlier stages of immune response anti-SRBC antibodies appeared as a thermolabile immune lysin, and finally as a thermostabile one ${ }^{22,34}$. Then, it has been noticed that this antibody activity (hemolysins) was rare in normal sera after inactivation at $56{ }^{\circ} \mathrm{C}^{34}$, and these criteria have been employed to distinguish normal from induced or "specific" antibody ${ }^{2,9,22}$. Previous studies indicated that in schistosomiasis the amount of anti-SRBC antibody differs from control individuals ${ }^{3,9}$. Moreover, by freezing and thawing the serum, it could be noticed a gradual loss of cytolytic anti-SRBC activity (data not shown) in the specimen, that may account for the rarity in which heterophile reactions of this kind is observed ${ }^{6}$. Reporting solely on some biological activity of the "naturally occurring" antibody in human sera, that lyses SRBC in the presence of complement system, our objective is to explain the logical reasoning behind some statistical tests, and to describe the main basic tests for comparing different conditions or characteristics. We also present some of the problems associated with their use and interpretation (see results). The statistical tests are not able to show that one condition or characteristic is the cause or is caused by another one. If the statistical method has absence of any complicated mathematics, this facilitates analyses of the data and might have a fundamental role in the interpretation with, if possible, practical effects. This rationale considers planning of the field and laboratory investigations of the data, and the interpretation of the results varies from practice of Medicine to Public Health programs until management of pharmaceutical products for testing potencial efficacy of health programs, and evaluating some aspect of drug response between cured or not cured individuals. Therefore, the present retrospective investigation besides interesting under statistics and immunoparasitological aspects should be interpreted with caution. In the absence of large enough groups of individuals, the medical data may be interpreted as a pilot study rather than representative of the population itself. In addition, there are important biases such as the absence of previous clinical conditions of the children and adult groups.

In human infections, it is known that the presence of hemolysins in heated sera correlated with the presence of mononucleosis virus infection, and in infection with several sorts of bacteria ${ }^{5,6}$. In mononucleosis viruses, the heterophile macroglobulin antibodies ${ }^{21}$ were found in a lower percentage in children than in adults ${ }^{24,26,32,33}$. Similarly, in infected sera it was noticed that in young individuals the injections of horse sera were not frequently followed of hemolysins for SRBC in heated $\operatorname{sera}^{27}$. Hitherto the lysins and the influence of age on antiSRBC lysins response have not been subject of investigation in human schistosomiasis. The present findings suggest that, in schistosomiasis, thermostability in hemolysins is dependent of the individuals'age grade, but it is not known how long it takes, following S. mansoni infection, for children to develop thermostabile anti-SRBC lysins.

It has been reported that isophile, induced or "specific" complement activating antibody titres (antibodies against adult worms) were lower in adult individuals with both $S$. mansoni and hookworm infections ${ }^{1}$. Herein, it is inquired whether the response difference between heterophile or naturally occurring hemolysin groups depends on the age grade with emphasis on hookworm and A. lumbricoides and/or $T$. trichuris. This approach does not appear in Immunology. Thus, association or lack of it among naturally occurring complement activating antibodies (hemolysins) and those geo-helminths groups are therefore of obvious medicine interest. In statistical sense this implies hypothetically that the hemolysin thermal characteristics neither influence nor are influenced by geo-helminths.

Sheep hemolysins were demonstrated in humans infected with hydatic cysts and injected with hydatic fluid ${ }^{18}$ and individuals injected with extracts of $A$. lumbricoides ${ }^{19}$. Under experimental conditions, high levels of sheep hemolysins are produced in pigs and rabbits infected with A. lumbricoides, and it was found to have no protective action against the infection ${ }^{31}$. However, schistosomotic individuals with thermostabile heterophile lytic antibody for SRBC should not be ascribed to exposure of individuals to geo-helminths. In fact, it was found thermal labile and thermostabile hemolysins in collected sera from individuals of two age grades irrespective to the presence of naturally occurring intestinal geo-helminths. If the inference to be derived was that anti-SRBC activity (hemolysins) might affect or be affected by any geo-helminths species, it is clear that one would need to be adjusted for age grade. There are two mainly reasons: the young group is known to be more prone to be infected by geo-helminths and the older one is more prone to present thermostabile hemolysins.

Noteworthy, thermostabile anti-SRBC lysins have been an important picture in certain bacterial infections ${ }^{6}$, mononucleosis viruses ${ }^{5}$, as well as in serum sickness ${ }^{13}$. In schistosomotic individuals, the $S$. mansoni eggs trapped in tissue is yet a predominant feature to be completely understood. Besides the fact that the pathophysiology of the hemolytic heterophile antibodies is unknown in schistosomiasis, in schistosomotic children the analysis of the fecal egg counting data showed the main effect of lysins stratified by thermo characteristics as follows: (1) The intensity of $S$. mansoni infection was higher in labile than in nonlabile antibodies. (2) Moreover, while more children tend to be located 


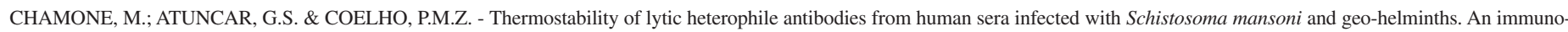
metric statistical analysis. Rev. Inst. Med. trop. S. Paulo, 48(3):157-165, 2006.

in lower egg count classes than in larger ones, the proportions of individuals classified as thermostable hemolysin increases with larger egg counting intervals. Then, hemolysin affects the number of children over the sequence of egg counts. These considerations are of immunological (ontogenesis of immune response, such as labile antibodies to non-labile ones), as well as environmental importance (spread of egg related with hemolysins). Further, it was investigated whether the differences in intensity of infection between the two hemolysins groups may be an attribute of the age rather than related to the hemolysins characteristics. From the result showing means for age \pm standard deviation in children with thermostabile $(11 \pm 2.2)$ and thermolabile $(10.9 \pm 2.1)$ hemolysin groups are quite similar the differences of mean egg count should not be ascribed to age in children with those two hemolysins types (data not shown).

Notedly, it has been reported that in adult groups, "specific" complement activating antibody titres (antibodies against adult worms) were lower in individuals with both $S$. mansoni and hookworm infections ${ }^{1}$, and this co-infection is associated with higher intensity of schistosomiasis $^{10,11}$. However, the prevalence of hookworms was similarly noticed in faeces obtained from thermolabile and thermostable schistosomiasis samples in both age grades examined. This is a problem of epidemiological statistic study and was evaluated in terms of Ecology and Immunology.

Hemolysin pattern did not change significantly in adults considered cured three months after oxamniquine treatment. In addition, as already previously observed ${ }^{25}$, in reference these treated sera collected from cured individuals, anticomplement activity was not detected, as reported from individuals with active schistosomiasis mansoni; moreover, the persistence of the hemolysins for SRBC in mononucleosis viruses has been reported, and in infected serum, as a rule, the hemolysin tended to return to normal rather soon ${ }^{13,14}$.

Altogether, the reasons for differences in intensity of schistosomiasis related to hemolysin characteristics are unknown, and this point is not pursued in this pilot study. Finally, it must be considered if the differences related with age grade in human heterophile responses are associated with ontogeny of the immunologic system and/or with the development of schistosomiasis. This might be important in immunopathology and immunoprotection. The clinical significance of the present preliminary data must be determined, and they illustrate the need for further studies in this field. The present communication also intended, at least in part, to attend the increasing number of publications dealing with Immunoparasitology, that require proper investigation to interpret the respective findings.

\section{RESUMO}

\section{Termo estabilidade de anticorpos líticos heterófilos de soro de pacientes infectados com Schistosoma mansoni e geo-helmintos. Uma análise estatística imuno-métrica}

Foram investigados anticorpos de soro humano que provocam lise de eritrócitos de carneiro em ensaios hemolíticos. O presente estudo mostra que a presença de anticorpos citolíticos termoestáveis contra hemácias de carneiro é dependente da infecção por Schistosoma mansoni e é mais freqüente em adultos do que em crianças. A característica termo estável da hemolisina em soros normais não é dependente da presença de Ascaris lumbricoides, Trichuris trichiura ou ancilostomídeos. Além disto, anticorpos heterófilos hemolíticos termo estáveis ativadores de complemento foram demonstrados em crianças com associação de altas cargas de ovos de S. mansoni. Os resultados foram obtidos usando-se os testes $\mathrm{z}$ - e o qui quadrado. $\mathrm{O}$ teste $\mathrm{z}$ - nos permite formular uma alternativa "one side", isto é, a tendência de um dos atributos. Por outro lado o teste do qui quadrado analisa a independência entre atributos usando-se uma tabela de contingência. Ao lado dos interessantes resultados obtidos no campo da esquistossomose mansoni, a abordagem estatística pode apontar novos caminhos para o tratamento de dados na ciência médica.

\section{REFERENCES}

1. ALVES-OLIVEIRA, L.; CHAMONE, M.; SILVEIRA, A.M.S. et al. - Quantitative complement fixation test in sera from patients with schistosomiasis and intestinal parasites. Ann. trop. Med. Parasit., 77: 541-542, 1983.

2. ALVES-OLIVEIRA, L.; CHAMONE, M.; MARQUES, C.A.; NASCIMENTO, B.C. \& COELHO, P.M.Z. - Antibodies reactivity in human schistosomal mansoni disease: detection and functional activity. Ann. trop. Med. Parasit., 82: 591-595, 1988 .

3. ANTUNES, L.J. \& PELLEGRINO, J. - Heterophile antibodies in schistosomiasis mansoni. J. Parasit., 53: 303-305, 1967.

4. ARMITAGE, P. \& BERRY, G. - Statistical methods in medical research. 3. ed. Oxford, Blackwell Science, 1994.

5. BERNSTEIN, A. - Infectious mononucleosis. Medicine (Baltimore), 19: 85-119, 1940.

6. BORNSTEIN, S. - Heterophile antibody reaction caused by bacterial infection. Ann. intern. Med., 16: 472-478, 1942.

7. BROWN Jr., W.M. \& HOLLANDER, M. - Statistics: a biomedical introduction. 2. ed. New York, John Wiley, 1977.

8. BUCK, A.A. - Infection and illness in the community. The diagnostic challenge of tropical diseases as seen by an epidemiologist. Amer. J. trop. Med. Hyg., 28: 171-179, 1979

9. CHAMONE, M.; OLIVEIRA, L.A.; COELHO, P.M.Z. et al. - Characterization of human heterophile hemolysins induced by Schistosoma mansoni infection. Mem. Inst. Oswaldo Cruz, 78: 257-267, 1983.

10. CHAMONE, M.; MARQUES, C.A. \& ALVES-OLIVEIRA, L. - Does ancylostomiasis favour the intensity of Schistosoma mansoni infection? Trans. roy. Soc. trop. Med. Hyg., 80: 1005, 1986.

11. CHAMONE, M.; MARQUES, C.A.; ATUNCAR, G.S.; PEREIRA, A.L.A. \& PEREIRA, L.H. - Are there interactions between schistosomes and intestinal nematodes? Trans. roy. Soc. trop. Med. Hyg., 84: 557-558, 1990.

12. CORREA-OLIVEIRA, R.; DUSSE, L.M.S.; VIANA, I.R.C. et al. - Human antibody responses against schistosomal antigens. Antibodies from patients with Ancyslostoma, Ascaris lumbricoides or Schistosoma mansoni infections react with schistosome antigens. Amer. J. trop. Med. Hyg., 38: 348-355, 1988.

13. DAVIDSOHN, I. - Heterophile antibodies in serum sickness. J. Immunol., 16: 259-273, 1929

14. DAVIDSOHN, I. - Further studies on heterophilic antibodies in serum sickness. J. Immunol., 18: 31-49, 1930.

15. DESHPANDE, J.V.; GORE, A.P. \& SHANUBHOGUE, A. - Statistical analysis of nonnormal data. New York, John Wiley, 1995 


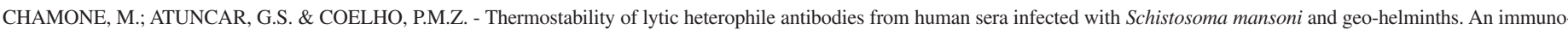
metric statistical analysis. Rev. Inst. Med. trop. S. Paulo, 48(3):157-165, 2006.

16. FLEISS, J.L. - Statistical methods for rates and proportions. 2. ed. New York, John Wiley, 1981.

17. GIBBONS, J.D. - Nonparametric statistical inference. 2 ed./rev. New York, Marcel Dekker, 1985.

18. GRANA, A. - Antibodies against sheep erythrocytes produced by the injection of hydatic liquid in patients with hydatic cyst. J. Immunol., 48: 203-270, 1944.

19. GRANA, A. - Antibodies against sheep erythrocytes and eosinophiles produced in subjects injected with saline extract of Ascaris lumbricoides suum. Rev. bras. Biol., 5: 81$86,1945$.

20. KATZ, N.; CHAVES, A. \& PELLEGRINO, J. - A simple device for quantitative stool thick-smear technique in schistosomiasis mansoni. Rev. Inst. Med. trop. S. Paulo, 14: 397-400, 1972.

21. LEE, C.L.; TAKAHASHI, T. \& DAVIDSOHN, I. - Sheep erythrocyte agglutinins and beef erythrocyte hemolysins in infectious mononucleosis serum. J. Immunol., 91: 783-790, 1963.

22. MICHAEL, J.G., WHITBY, J.L. \& LANDY, M. - Studies on natural antibodies to gramnegative bacteria. J. exp. Med., 115: 131-146, 1962.

23. MOOD, A. - Introduction to the theory of statistics. New York, McGraw-Hill, 1950.

24. MONSO PUIGCERCOS, G.; POU FERNANDES, J.; TRUJILLO ISERN, G.; JUNCOSA MORROS, T. \& CAMBRA LASAOSA, F.G. - Infectious mononucleosis in childhood. An. esp. Pediat., 36: 219-222, 1992.

25. NASCIMENTO, B.C. \& CHAMONE, M. - The separation of the complement inhibitor from patients with schistosomiasis or Chagas' disease by gel filtration on Sephadex G-200: a preliminary study. Braz. J. med. biol. Res., 21: 295-299, 1988.
26. NIKOSKELAINEN, J. \& HANNINEN, P. - Antibody response to Epstein-Barr virus in infectious mononucleosis. Infect. Immun., 11: 42-45, 1975.

27. RAMSDELL, S.G. \& DAVIDSOHN, I. - The toxicity of human serum for the guinea pig. Serum in various clinical conditions. J. Immunol., 18: 473-483, 1930.

29. SACHS, L. - Applied statistics: a handbook of techniques. 2. ed. New York, SpringerVerlag, 1984

30. SOKAL, R.R. \& ROHLF, F.J. - Biometry: the principles and practices of statistics in biological research. 3. ed. New York, W.H. Freeman, 1995.

31. SOULSBY, E.J.L. - Studies on the heterophile antibodies associated with helminth infections. II. Heterophile antibody in Ascaris lumbricoides infection in pigs. J. comp. Path., 68: 71-81, 1958.

32. STYCZYNSKI, J.; WASEWICZ, A. \& BALCAR-BORON, A. - Diagnosis of mononucleosis in children. Wiad. Lek., 51: 46-50, 1998.

33. SUMAYA, C.V. \& ENCH, Y. - Epstein-Barr virus infectious mononucleosis in children II. Heterophile antibody and viral-specific responses. Pediatrics, 75: 1011-1019, 1985 .

34. TEALE, F.H. - Some observations on the question of the various manifestations of antibody activity being due to separate antibodies of an immune substance acting differently under various conditions. J. Immunol., 28: 241-278, 1930.

35. ZAR, J.H. - Biostatistical analysis. 3. ed. Upper Saddle River, Prentice Hall, 1996.

Received: 21 June 2005

Accepted: 6 February 2006 